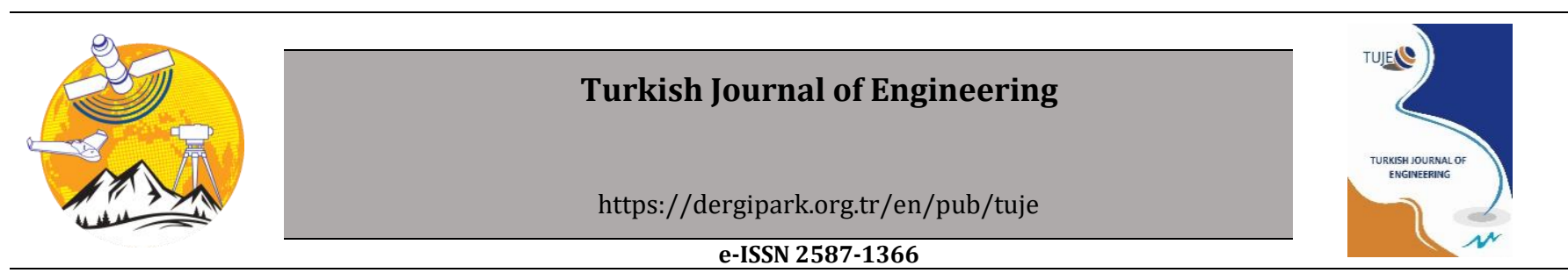

\title{
Pioneering institutions in sector on real estate appraisal
}

\author{
Fatih Taktak $^{* 1}$, Mahir Serhan Temiz ${ }^{1}$ \\ ${ }^{1}$ Usak University, Faculty of Engineering, Department of Surveying Engineering, Ușak, Turkey
}

\author{
Keywords \\ Real estate appraisal \\ Network analysis \\ Organizational communication \\ Interoperability \\ Awareness
}

\begin{abstract}
The institutions that take the leading role in the evaluation of the real estate should be determined. Real estate valuation takes place in a multi-headed organizational structure and is benefited from institutions in both the public and private sectors. The method of determining the institutions will be examined through the social network analysis methodology of the network of relations between public institutions and the private sector. With the numerical and visual analyzes the following questions will be examined: "Which is the director and responsible institution to undertake the task of collecting the institutional structure under one roof?", Which is the institution that uses the real estate appraisal results most in their works?, Which institution is the most cooperating in acquiring data on real estate appraisal?, Which are the most known institutions that make real estate appraisal?, Which of the institutions that make real estate appraisal are most trusted?". The study will be conducted in order to find answers given to the related questions. As a result, relations between institutions engaged in real estate appraisal business are assessed by social network analysis and interoperability issuing "awareness network" will be put forward.
\end{abstract}

\section{INTRODUCTION}

In the competitive and variable environment of life in recent years, it has become compulsory for any service providing process to be fast, quality and economical in general. A new approach to service provisioning is possible only if different service providers can cooperate or collaborate effectively. Interoperability infrastructures are required for this (Zutshi et al. 2012; Charalabidis et al. 2015; Diallo et al. 2016). TNCIS (Turkey National Geographic Information System) and services not in the field, in all other areas, such as egovernment has emerged in a very significant way (Güney et al. 2015; Polat et al. 2015; Ozbek et al. 2016; Saralioğlu et al. 2019).

According to significant studies carried out regarding today's public and private sector structures show that requires active collaborations, both functional and physical and within hierarchical boundaries (Vaubel 2016; Smith and Wen 2017; Wang et al. 2019). Such a study is carried out through informal networks between institutions. In this study, collaborations and communication networks are put forward by using social (organizational) network analysis and suggestions are introduced (Tichy et al. 1979; Borgatti and Molina 2003; Carrington et al. 2005; Ujwary-Gil 2019). The awareness network can be established as to whether or not the institutions are aware of each other's data and which exchange data among themselves and which institutions are represented with network analysis that often happens (Thibaut et al. 2012; Barabási 2016; Jones et al. 2017). These two analyses can be integrated and interpreted.

Throughout the country, public and private sector institutions that make property appraisal were identified, and a network of invisible relationships between them were uncovered and thus; it was attempted to determine the premise institution to undertake the task of gathering under a single roof in the evaluation of real estate with the obtained numerical and visual analysis data (Friedman et al. 2017; MacGregor et al. 2018).

In this study, targeted benefits across Turkey by determining the roofing Institution of real estate valuation are summarized below:

Determination and registration of real estate values is necessary for the provision of tax justice and planned development in the country. It is important to know the 
value of real and legal persons ' private property in terms of recording economic transactions. It is important to determine the value of the real estate in terms of expropriation, housing sector, reduction of company assets and litigation load, to arrange expert reports on real estate values in cases based on Geographical Information Systems, scientific technical data, and to carry out the expropriation operations fairly and smoothly. Urban transformation projects of public, the property rights of real and legal persons to be treated with respect, urban rent and the city of society, social peace, and peace in terms of a public service that is the view of stakeholders that must be performed immediately.

\section{REAL ESTATE VALUATION}

Planning of cities and economic development of the reconstruction plans are only possible by evaluating the real estate with appropriate methods (Yu 2016; Kauko 2018; Ertas 2019; Nanda 2019). Moreover, the revaluation of the real estate value increases arising from public investments can be realised by evaluating these properties before and after the investment (Wang et al. 2018). Real estate appraisal is also of great importance in terms of selecting new settlement areas, consolidating of fragmented parcels in urban areas and arranging them following the plan, clarity and trust of real estate markets, monitoring price changes in the market, guiding real estate buyers, sellers, owners and entrepreneurs (Lucius 2001; Krause and Bitter 2012). Real estate valuation is one of the essential economic bases of developed societies. In our country, real estate appraisal transactions are not dependent on any standard, and they have adverse effects on economic and social balances. Since the real estate appraisal system still does not exist, many valuation cases have come to our country, economically there are significant tax losses of the state, and there are many differences in the real estate market. Due to the increasing number of discussions in this subject and the increasing need for information related to the subject, it is necessary to provide a more healthy system of valuation of real estates (Whitney et al. 2009; Smith 2016; Unel et al. 2017). The same or similar activities for real estate can be realised by more than one institution. In our country, inter-institutional coordination is of great importance in terms of preventing repetitive work and, if necessary, sharing of acquired experiences. On the other hand, according to the administrators and employees of the institutions operating in the real estate, there is no effective coordination among the institutions in our country (Iversen et al. 2016; Çay et al. 2017; Lundsgaarde et al. 2018).

\section{SOCIAL NETWORK ANALYSIS}

The earliest findings of SNA are known to be found in the writings of ancient Greek scholars. The primary development regarding this area started in the 1930s with studies in different fields progressing independently of each other (Scott 1988; Wasserman and Faust 1994; Knoke and Yang 2019). Network analysis which is being examined in the fields of psychology, sociology, mathematics, statistics and informatics, is today a research area which is mentioned with its applications spreading in a comprehensive framework including social scientists, informatics experts, politicians, economists, sociologists and mathematicians (Freeman 2004; Carrington et al. 2005; Borgatti et al. 2009). A study by the American scientists Moreno and Jennings (1938), a sociogram or diagrammatic map benefiting dots and lines to illustrate social relations has been adopted as an important starting point for the development of social network analysis. In his study of the foundations of sociometry, Jacob Moreno used methods including graphical representations, which allowed individuals or social groups to identify the relationships within quantifiable quantitative parameters. Moreno focused on the relationships between people rather than people and has made concrete ideas about the social network or social texture that had not been previously apparent (Freeman 1996; Borgatti and Ofem 2010)

SNA is a method of investigating the structure of social relationships that exist between people. ; It is also an analytical framework for examining the relationships between social entities. Through SNA, the social network is defined as the relationship between social actors, mapping and surveying studies. The SNA is based on the assumption that the importance of the relationship between interactive groups. Social entities, defined as actors, are represented as nodes in the plane. Social relations are a result of people's experiences, in other words, how it felt and that also affects the subjective field to which information or resources available with these experiences. The benefit of the SNA is that it allows us to examine the relationships among people and then examine their interconnectedness. SNA is a method that is frequently used to reveal social dynamics in sociological and organizational studies. Identifying information, sharing patterns in education and online learning environments are used to understand social capital accumulation in the network. Since knowledge is an essential factor in the formation of wealth, economic actors want to direct information to themselves. It is one of the reasons that make SNA valuable. The answer to the question of the conditions under which actors who are close to knowledge can use this situation as an advantage can be obtained through the SNA (Freeman et al. 2017; Borgatti et al. 2018).

\subsection{The Criteria of Social Network Analysis}

In the process of examining the network structure with the SNA, it is observed that SNA focuses on the connections between the actors rather than the attributes of the network. During the analysis process, several values obtained as a result of identifying and digitizing the relationships between actors in the network are called criteria. With the criteria used in the SNA is provided by comparing networks, identifying types, analyzing the complex structure of networks, and making the network understandable. By determining criteria such as density, centrality for a network, the position, connections and weaknesses or strengths of an actor in the social network can be revealed. Various 
criteria can be achieved by performing SNA at different levels when the analysis is done for the whole network. There are different criteria for examining subgroups in the network and in evaluating each actor in the network. Although they have different names, basically each node in a network is called a node, while linking connections/relationships between entities. In visualization applications, the connections between the two nodes are generally expressed as "edge", since they are indicated by a line connecting the nodes (Wasserman and Faust 1994; Carrington et al. 2005; Knoke and Yang 2019).

Table 1. Social network mechanism measures used for actors (Jablin and Putnam 2001; Taktak and Demir 2019)

\begin{tabular}{ll}
\hline Measure & Definition \\
\hline Degree & $\begin{array}{l}\text { The number of direct connections to other } \\
\text { actors. }\end{array}$ \\
Indegree & $\begin{array}{l}\text { Number of connections of other elements to } \\
\text { the actor (receiving connections). }\end{array}$ \\
The number of connections of the actor to \\
other elements (sending connections).
\end{tabular}

In order for the SNA to be carried out, a number of data must be available describing Which actors are connected. Mathematical measurement and calculation methods are used to identify and analyze the social network mechanism created after the introduction of network relation data; It is differentiated from the statistical methods used in data analysis of any quantitative research in the field of social sciences. In the social network analysis, specific measurement methods are used to explain the position of the actors in the network and formed as a whole in order to define the network mechanism. In order to explain the relations between the actors and the network mechanism, Jablin and Putnam discussed the methods of measurement in four groups. These are (Jablin and Putnam 2004);

- Measurements of social network mechanism used for relationships: It provides the analysis of the structure of the relations between the actors in a network organization and the determination of the extent of the actors within the network. It is also used to describe the qualitatively differentiated aspects of network relationships.

- Measurements of social network mechanism used for actors: The hierarchical structure of a network mechanism is very important in terms of determining the power relations and determining the communication patterns.

- The roles of the actors in the network mechanism: It shows the tasks played by the actors on the network.

Measurements of the social network mechanism used to identify network devices: It is used to define the network features as a whole. Information such as the size or density of the network mechanism generated. Also, it is after entering the data by determining network relationships. In organizational research, it provides the determination of the effectiveness of established relations within an area of activity.

Table 2. The role of actors in network (Jablin and Putnam 2001; Taktak and Demir 2019)

\begin{tabular}{ll}
\hline Measure & Definition \\
\hline Star & $\begin{array}{l}\text { An actor had a high centrality in the } \\
\text { network. }\end{array}$ \\
Liaison & $\begin{array}{l}\text { An actor who provides the relationship of } \\
\text { two or more groups that cannot otherwise } \\
\text { be related to each other. }\end{array}$ \\
Bridge & $\begin{array}{l}\text { An actor who is a member of two or more } \\
\text { groups. }\end{array}$ \\
An actor was controlling the flow of \\
information with a single connection \\
between one part of the network and the \\
other part.
\end{tabular}

\section{IMPLEMENTATION}

Based on the institutions shown in Table 3 , the cooperation of the institutions, which have a network of relations within the scope of real estate appraisal, is examined by using SNA method.

Survey questions were asked to each institution in Table 3 in the form of face-to-face interviews to the relevant experts on Real Estate Appraisal. For five survey questions which are functional in terms of SNA method, the numerical values given by the people who filled out the questionnaire were prepared as a separate Table. The obtained data were statistically and visually evaluated, and the evaluations were performed by Gephi 0.9.1 software which is one of the SNA software and preferred for scientific publications. As the sample of the study, 26 organizations in public and private sectors that used or generated spatial data were selected (Tab. 3).

Likert type scale was used in this study. Based on the recommendations, an odd-numbered scale was used. Additionally, the scale of 0-8 was chosen to show the weight in the network figures clearly. As the study would have a network mechanism sample, the sample was selected to be limited in space. The position-based approach was used to define the limits of samples (Burt 
and Minor 1983). In the position-based approach, the presence of a membership relation for the network in which actors are in can be proved. The reason why limited space is used in the study is that the number of researched and compared relations increase exponentially with the number of volunteers. Therefore studies in which sociometric data is collected and use a matrix approach usually have 40 or fewer samples (Seevers et al. 2015). For that reason, it can be concluded that the sample used in this study is adequate for sociometric research. All of the volunteers in the sample were engineers or people with a technical job.

Table 3. Organizations associated with real estate valuation In Usak Province (Taktak 2013)

\begin{tabular}{|c|c|}
\hline Name of Institution & Abbreviation \\
\hline Usak Municipality & UM \\
\hline Special Provincial Administration & SPA \\
\hline State Hydraulic Works & SHW \\
\hline Housing Development Administration & HDA \\
\hline Forest Management Directorate & FMD \\
\hline The Directorate of Highways & DH \\
\hline $\begin{array}{l}\text { Department of Environment and } \\
\text { Urbanization }\end{array}$ & DEU \\
\hline $\begin{array}{l}\text { Directorate of Title Deed Registry and } \\
\text { Cadastre }\end{array}$ & DTDRC \\
\hline Foundations & $\mathrm{F}$ \\
\hline Turkish Electricity Distribution Company & TEDC \\
\hline Governorship & G \\
\hline Provincial Directorate of Agriculture & PDA \\
\hline Real Estate Agent & REA \\
\hline Banks & $\mathrm{B}$ \\
\hline National Real Estate Department & NRED \\
\hline $\begin{array}{l}\text { Licensed Bureau of Surveying } \\
\text { Engineering }\end{array}$ & LBSE \\
\hline Telecom Directorate & TD \\
\hline Directorate of Disaster Affairs & DDA \\
\hline Independent Survey and Cadastre Office & ISCO \\
\hline Chamber of Commerce & $\mathrm{CC}$ \\
\hline Chamber of Agriculture & CA \\
\hline Directorate of Museums & DM \\
\hline University of Usak & UU \\
\hline Courts & $\mathrm{C}$ \\
\hline Natural Gas Distribution Company & NGDC \\
\hline $\begin{array}{l}\text { Directorate of Provincial Food } \\
\text { Agriculture and Livestock }\end{array}$ & DPFAL \\
\hline
\end{tabular}

\subsection{Showing Relations of Cooperation, Trust and Data Sharing Within Social Network}

Without proper coordination and cooperation between institutions, it is not possible to reach institutional and social goals. Stability and development are realised through inter-agency cooperation and compliance. When corporate relations are carried out, healthily, stability and social development become easier. The institutions need to obtain public trust towards the decisions and actions they take and to get approval and support from their target groups. It is essential to establish public trust and pay due attention to institutions operating in the public sector. Because public institutions are state governing bodies, they have the responsibility of both the administrative power and the public benefit that this administrative power brings. Effective data sharing of organizations is an interoperability system that provides instant access to and use of services. The data needed by the institutions to carry out their activities; It is a comprehensive application that tries to create a fast, economical and efficient way to reach it. Data-based technological applications are increasing day by day and the number of users increases, as well.

Table 4. Social network analysis survey questions

\begin{tabular}{|c|c|c|}
\hline No & $\begin{array}{l}\text { Relations which show } \\
\text { the network potential } \\
\text { for data sharing }\end{array}$ & disagree $\longleftrightarrow$ agree \\
\hline 1 & $\begin{array}{l}\text { Which are the most } \\
\text { known institutions } \\
\text { engaged in the } \\
\text { business of real estate } \\
\text { valuation? }\end{array}$ & $\begin{array}{lllllllll}0 & 1 & 2 & 3 & 4 & 5 & 6 & 7 & 8\end{array}$ \\
\hline 2 & $\begin{array}{l}\text { What is the institution } \\
\text { that uses the real } \\
\text { estate valuation data } \\
\text { in its work? }\end{array}$ & $\begin{array}{lllllllll}0 & 1 & 2 & 3 & 4 & 5 & 6 & 7 & 8\end{array}$ \\
\hline 3 & $\begin{array}{l}\text { Which institutions are } \\
\text { cooperated most to } \\
\text { obtain the data related } \\
\text { to real estate valuation } \\
\text { ? }\end{array}$ & $\begin{array}{llllllllll}0 & 1 & 2 & 3 & 4 & 5 & 6 & 7 & 8\end{array}$ \\
\hline 4 & $\begin{array}{l}\text { Which of the } \\
\text { institutions that make } \\
\text { real estate appraisal } \\
\text { are trusted the most? }\end{array}$ & $\begin{array}{lllllllll}0 & 1 & 2 & 3 & 4 & 5 & 6 & 7 & 8\end{array}$ \\
\hline 5 & $\begin{array}{l}\text { Which is the guiding } \\
\text { and responsible body } \\
\text { to undertake the task } \\
\text { of gathering } \\
\text { institutional } \\
\text { structuring under a } \\
\text { single roof? }\end{array}$ & 0 \\
\hline
\end{tabular}

Today, for data sharing between institutions, it is necessary to determine the functional, physical and hierarchical boundaries of institutions and to ensure practical cooperation between them. Social networks are the systems that will reveal the invisible cooperation between institutions. SNA, which can be expressed as the digitization and scientific nation of the relations between the actors, is used to transform the existing networks of relations between organizations or organizations into numerical data. According to the digitized data, the shape and characteristics of the network obtained will reveal the efficiency of the institutional or inter-institutional communication network. It also guides taking necessary measures or providing support on the issues analysed.In this study, in order to be able to have an idea about the functioning of the institutions. Besides, the way in which they are perceived by those concerned, an application has been made at the local dimension. In the central district of Uşak province, the existing relationship network between public institutions, local administrations, private sector and real estate appraisal and business sectors that produce data on real estate valuation is presented. The resulting existing networks are aimed to obtain information about the status of the real estate appraisal at the national scale. In the thesis, the relationship between the institutions was examined from a social point of view. It is not from a technical point of view. With this examination, a study has been carried out which can reveal the interoperability of the 
institutions which are not aware of them and which do not depend on a particular rule. In the research, social network analysis is examined, and the organizational structure between institutions is put forward.In this context, the survey questions $1,2,3,4,5$ given in Table 4, which would reveal the cooperation within the network, were directed to the concerned.

Survey Question 1: Each organization that uses or produce data on real estate valuation was asked the question "Which are the most known institutions engaged in the business of real estate valuation?". Network and centrality graphs were created using the data obtained from the answers to this question. Actors and data access network among actors is shown in Fig. 1.

The numerical value of the frequency of public institutions meeting with each other was calculated as 415. The maximum number of bonds that can occur in the network is $650(n(n-1)=26.25=650)$. Based on this number of bonds, the overall density of the network was calculated as $415 / 650=0.638$. For a network of 26 public institutions, this value is seen to have a density above average. $63.8 \%$ of the maximum number of ties that can occur between the actors are in the network. It can be said that public institutions' awareness of real estate valuation among each other is above the middle level.

The calculated "in degree, out degree, in closeness, out closeness, in eigenvalues, out eigenvalues and between values" and the institutions with the highest and lowest values are shown in Table 4, according to the answers of the public institutions, namely the actors, to the first question of the survey.

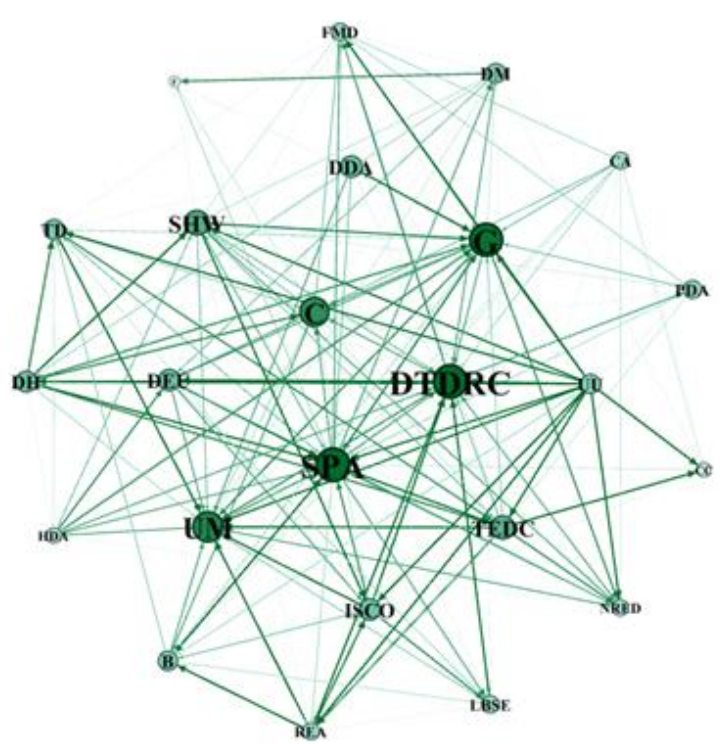

Figure 1. Network map of actors and links between actors according to answers to the first question

Table 4. "Which one is known to most real estate appraisal organization?" In-out degree, in-out closeness, in-out eigenvalues and between proximity values results for this question are:

\begin{tabular}{lllllllll}
\hline No & Institutions & OutDeg & Indeg & OutClose & InClose & OutEigen & InEigen & Between \\
\hline 1 & UM & 2.28 & 5.88 & 0.806 & 1 & 0.195 & 0.411 & 0.03 \\
2 & SPA & 4.36 & 4.56 & 1 & 1 & 0.338 & 0.313 & 0.068 \\
3 & SHW & 2.84 & 3.04 & 0.806 & 1 & 0.239 & 0.217 & 0.036 \\
4 & HDA & 1.88 & 0.76 & 0.694 & 0.658 & 0.188 & 0.061 & 0.003 \\
5 & FMD & 1.16 & 1.76 & 0.641 & 0.735 & 0.111 & 0.119 & 0.002 \\
6 & DH & 2.6 & 2.16 & 0.694 & 0.926 & 0.247 & 0.169 & 0.01 \\
7 & DEU & 2.56 & 1.76 & 0.758 & 0.658 & 0.232 & 0.156 & 0.007 \\
8 & DTDRC & 3.12 & 6.36 & 0.962 & 1 & 0.248 & 0.441 & 0.059 \\
9 & F & 1.2 & 0.48 & 0.641 & 0.568 & 0.115 & 0.039 & 0 \\
10 & TEDC & 2.16 & 1.92 & 0.694 & 0.781 & 0.18 & 0.147 & 0.006 \\
11 & G & 3.56 & 3.84 & 1 & 1 & 0.291 & 0.261 & 0.068 \\
12 & PDA & 1.48 & 0.76 & 0.714 & 0.595 & 0.132 & 0.079 & 0.001 \\
13 & REA & 1.56 & 3.8 & 0.658 & 1 & 0.14 & 0.272 & 0.006 \\
14 & B & 1.6 & 2.32 & 0.641 & 0.962 & 0.149 & 0.187 & 0.01 \\
15 & NRED & 1.16 & 2.48 & 0.61 & 0.862 & 0.119 & 0.218 & 0 \\
16 & LBSE & 1.36 & 1.2 & 0.694 & 0.595 & 0.128 & 0.143 & 0.003 \\
17 & TD & 1.8 & 1.48 & 0.714 & 0.625 & 0.16 & 0.137 & 0.003 \\
18 & DDA & 1.84 & 0.64 & 0.806 & 0.581 & 0.171 & 0.071 & 0.003 \\
19 & C & 2.48 & 2.04 & 0.962 & 0.658 & 0.204 & 0.183 & 0.019 \\
20 & ISCO & 2.12 & 2.16 & 0.694 & 0.694 & 0.186 & 0.197 & 0.005 \\
21 & CC & 0.92 & 1.08 & 0.581 & 0.658 & 0.093 & 0.07 & 0 \\
22 & CA & 1.8 & 0.36 & 0.694 & 0.568 & 0.151 & 0.034 & 0 \\
23 & DM & 2.12 & 0.64 & 0.781 & 0.595 & 0.188 & 0.065 & 0.004 \\
24 & UU & 3.76 & 0.96 & 0.862 & 0.962 & 0.32 & 0.069 & 0.041 \\
25 & DPFAL & 1.52 & 0.88 & 0.714 & 0.581 & 0.134 & 0.11 & 0.001 \\
26 & NGDC & 2.04 & 1.96 & 0.694 & 0.758 & 0.167 & 0.151 & 0.004 \\
\hline
\end{tabular}

Survey Question 2: Each organization that uses or produce data on real estate valuation was asked the question "Which institution uses the real estate valuation data in its work ?" and network and centrality graphs were created using the data obtained from the answers to this question. Actors and data access network among actors is shown in Fig. 2.
The numerical value of the frequency of public institutions meeting with each other was calculated as 415. The maximum number of bonds that can occur in the network is $650(n(n-1)=26.25=650)$. Based on this number of bonds, the overall density of the network was calculated as $519 / 650=0.798$. For a network of 26 public institutions, this value is seen to have a density above average. $79.8 \%$ of the maximum number of ties that can 
occur between the actors are in the network. It can be said that the public institutions use real estate valuation studies among each other, and it is above the middle level.

Survey Question 3: Each organization that uses or produce data on real estate valuation was asked the

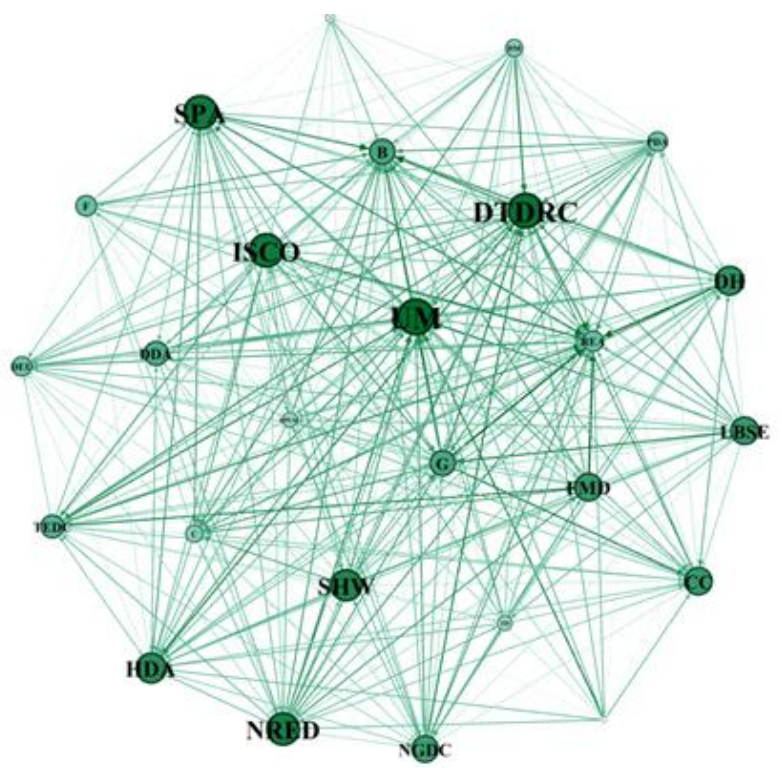

Figure 2. Network map of actors and links between actors according to answers to the second question question "Which institutions have cooperated the most to obtain the data relating to real estate valuation?". Network and centrality graphs were created using the data obtained from the answers to this question. Actors and data access network among actors is shown in Fig. 3.

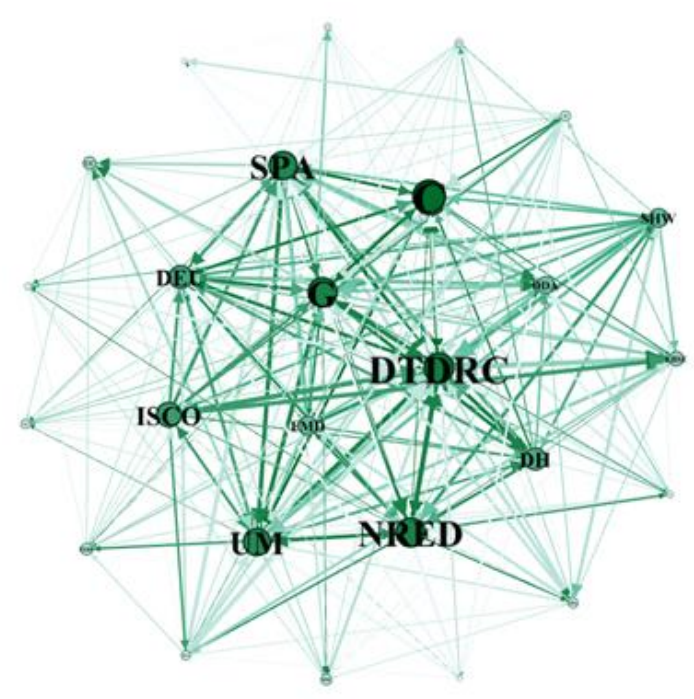

Figure 3. Network map of actors and links between actors according to answers to the third question

Table 5. "Which institution uses the real estate valuation data in its work?" In-out degree, in-out closeness, in-out eigenvalues and between proximity values results for this question are:

\begin{tabular}{|c|c|c|c|c|c|c|c|c|}
\hline No & Institutions & OutDeg & Indeg & OutClose & InClose & OutEigen & InEigen & Between \\
\hline 1 & UM & 3.92 & 5.24 & 1 & 1 & 0.225 & 0.278 & 0.03 \\
\hline 2 & SPA & 4.64 & 3.84 & 1 & 0.926 & 0.255 & 0.216 & 0.019 \\
\hline 3 & SHW & 3.88 & 3.32 & 0.962 & 0.893 & 0.222 & 0.193 & 0.018 \\
\hline 4 & HDA & 3.48 & 4.48 & 0.833 & 1 & 0.207 & 0.245 & 0.016 \\
\hline 5 & FMD & 3.96 & 3.12 & 0.926 & 0.833 & 0.225 & 0.183 & 0.007 \\
\hline 6 & $\mathrm{DH}$ & 4.52 & 3.04 & 1 & 0.806 & 0.248 & 0.177 & 0.008 \\
\hline 7 & DEU & 2.56 & 3.12 & 0.735 & 0.833 & 0.153 & 0.175 & 0.003 \\
\hline 8 & DTDRC & 4.48 & 5.4 & 1 & 0.962 & 0.245 & 0.289 & 0.023 \\
\hline 9 & $\mathrm{~F}$ & 3.04 & 1.44 & 0.962 & 0.676 & 0.175 & 0.079 & 0.002 \\
\hline 10 & TEDC & 3.56 & 3.24 & 0.806 & 0.833 & 0.211 & 0.198 & 0.005 \\
\hline 11 & G & 4.64 & 3.44 & 0.962 & 0.758 & 0.257 & 0.181 & 0.005 \\
\hline 12 & PDA & 4.28 & 1.88 & 1 & 0.641 & 0.241 & 0.106 & 0.001 \\
\hline 13 & REA & 1.88 & 6 & 0.658 & 1 & 0.109 & 0.323 & 0.002 \\
\hline 14 & B & 2.4 & 5.72 & 0.735 & 1 & 0.142 & 0.306 & 0.007 \\
\hline 15 & NRED & 3.88 & 4.12 & 0.893 & 1 & 0.226 & 0.215 & 0.018 \\
\hline 16 & LBSE & 4 & 2.28 & 1 & 0.781 & 0.23 & 0.126 & 0.006 \\
\hline 17 & TD & 2.4 & 2.4 & 0.714 & 0.758 & 0.139 & 0.136 & 0.001 \\
\hline 18 & DDA & 3.36 & 2.56 & 0.893 & 0.781 & 0.198 & 0.146 & 0.004 \\
\hline 19 & $\mathrm{C}$ & 1.44 & 3.68 & 0.61 & 1 & 0.072 & 0.198 & 0.003 \\
\hline 20 & ISCO & 4.56 & 3.84 & 1 & 0.926 & 0.255 & 0.212 & 0.022 \\
\hline 21 & $\mathrm{CC}$ & 2.6 & 4.4 & 0.781 & 1 & 0.152 & 0.244 & 0.01 \\
\hline 22 & $\mathrm{CA}$ & 1.48 & 1.08 & 0.676 & 0.694 & 0.076 & 0.058 & 0 \\
\hline 23 & DM & 3.24 & 1.2 & 0.893 & 0.658 & 0.183 & 0.069 & 0 \\
\hline 24 & UU & 1.84 & 0.76 & 0.625 & 0.694 & 0.1 & 0.042 & 0.001 \\
\hline 25 & DPFAL & 1.88 & 3.08 & 0.641 & 0.862 & 0.106 & 0.17 & 0.002 \\
\hline 26 & NGDC & 3.84 & 3.08 & 0.962 & 0.781 & 0.221 & 0.171 & 0.005 \\
\hline
\end{tabular}


Table 6. "Which institutions are cooperated with the most to obtain the data relating to real estate valuation?" in-out degree, in-out closeness, in-out eigenvalues and between proximity values results for this question are:

\begin{tabular}{|c|c|c|c|c|c|c|c|c|}
\hline No & Institutions & OutDeg & Indeg & OutClose & InClose & OutEigen & InEigen & Between \\
\hline 1 & UM & 2.48 & 4.52 & 0.735 & 1 & 0.241 & 0.346 & 0.031 \\
\hline 2 & SPA & 2.8 & 4.68 & 0.758 & 1 & 0.254 & 0.354 & 0.032 \\
\hline 3 & SHW & 2.84 & 1.72 & 0.714 & 0.735 & 0.275 & 0.169 & 0.009 \\
\hline 4 & HDA & 2.32 & 0.44 & 0.658 & 0.556 & 0.23 & 0.055 & 0.001 \\
\hline 5 & FMD & 2.32 & 1.4 & 0.694 & 0.758 & 0.23 & 0.134 & 0.013 \\
\hline 6 & DH & 2.4 & 2.28 & 0.714 & 0.833 & 0.241 & 0.222 & 0.02 \\
\hline 7 & DEU & 2.48 & 3.28 & 0.714 & 0.862 & 0.251 & 0.275 & 0.021 \\
\hline 8 & DTDRC & 2.88 & 5.76 & 0.806 & 1 & 0.265 & 0.422 & 0.046 \\
\hline 9 & $\mathrm{~F}$ & 0.68 & 0.72 & 0.581 & 0.625 & 0.068 & 0.073 & 0.004 \\
\hline 10 & TEDC & 1.08 & 0.92 & 0.641 & 0.658 & 0.107 & 0.079 & 0.004 \\
\hline 11 & G & 2.76 & 4.12 & 0.781 & 1 & 0.258 & 0.308 & 0.048 \\
\hline 12 & PDA & 1.4 & 1.08 & 0.625 & 0.641 & 0.15 & 0.112 & 0.002 \\
\hline 13 & REA & 2.36 & 0.68 & 0.714 & 0.556 & 0.234 & 0.048 & 0.002 \\
\hline 14 & B & 2 & 0.96 & 0.676 & 0.595 & 0.185 & 0.048 & 0.01 \\
\hline 15 & NRED & 2.4 & 3.4 & 0.833 & 0.926 & 0.229 & 0.295 & 0.061 \\
\hline 16 & LBSE & 2.04 & 1.52 & 0.735 & 0.625 & 0.212 & 0.149 & 0.008 \\
\hline 17 & TD & 1.64 & 0.24 & 0.625 & 0.556 & 0.172 & 0.022 & 0.001 \\
\hline 18 & DDA & 2.04 & 1.6 & 0.758 & 0.658 & 0.204 & 0.171 & 0.012 \\
\hline 19 & C & 1.84 & 3.48 & 0.926 & 0.962 & 0.174 & 0.278 & 0.09 \\
\hline 20 & ISCO & 2.52 & 1.76 & 0.893 & 0.735 & 0.249 & 0.166 & 0.038 \\
\hline 21 & CC & 1.16 & 1.16 & 0.625 & 0.694 & 0.115 & 0.132 & 0.007 \\
\hline 22 & $\mathrm{CA}$ & 0.64 & 0.36 & 0.625 & 0.556 & 0.063 & 0.029 & 0.002 \\
\hline 23 & DM & 1.08 & 0.6 & 0.694 & 0.595 & 0.109 & 0.072 & 0.003 \\
\hline 24 & UU & 0.68 & 0.76 & 0.61 & 0.641 & 0.072 & 0.09 & 0.001 \\
\hline 25 & DPFAL & 0.84 & 0.32 & 0.658 & 0.556 & 0.084 & 0.026 & 0.001 \\
\hline 26 & NGDC & 0.76 & 0.68 & 0.595 & 0.625 & 0.083 & 0.053 & 0.001 \\
\hline
\end{tabular}

The numerical value of the frequency of public institutions meeting with each other was calculated as 368 . The maximum number of bonds that can occur in the network is $650(n(n-1)=26.25=650)$. Based on this number of bonds, the overall density of the network was calculated as $368 / 650=0.566$. For a network of 26 public institutions, this value is seen to have a density above average. $56.6 \%$ of the maximum number of ties that can occur between the actors are in the network. For public institutions it can be said that the intensity of establishing cooperation with each other in obtaining data on real estate valuation is at a moderate level.

Survey Question 4: Each organization that uses or produce data on real estate valuation was asked the question " Which of the institutions that make real estate appraisal is trusted the most ?". Network and centrality graphs were created using the data obtained from the answers to this question. Actors and data access network among actors is shown in Fig. 4.

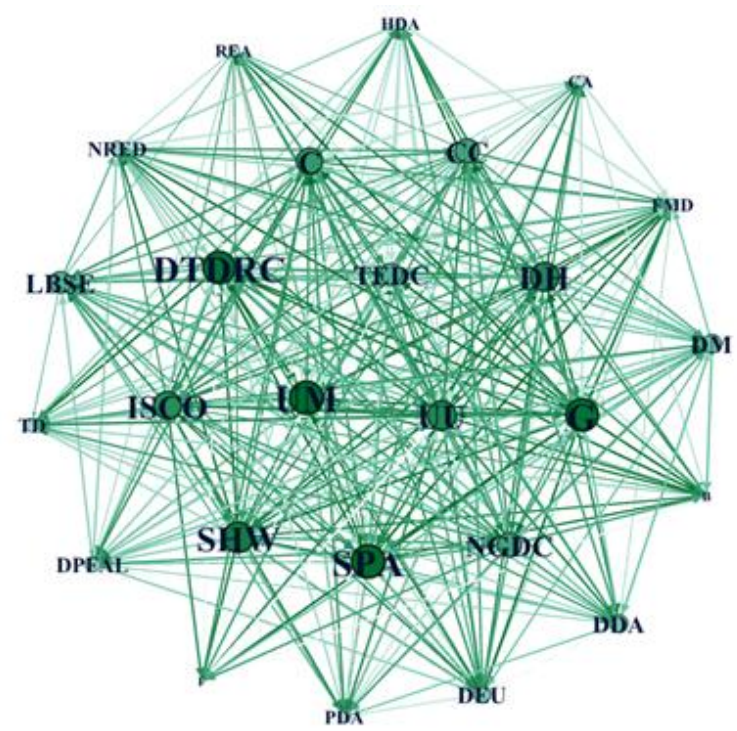

Figure 4. Network map of actors and links between actors according to answers to the fourth question 
Table 7. "Which of the institutions that make real estate appraisal is trusted the most ?" in-out degree, in-out closeness, in-out eigenvalues and between proximity values results for this question are:

\begin{tabular}{|c|c|c|c|c|c|c|c|c|}
\hline No & Institutions & OutDeg & Indeg & OutClose & InClose & OutEigen & InEigen & Between \\
\hline 1 & UM & 6.72 & 6.32 & 0.962 & 0.862 & 0.248 & 0.241 & 0.041 \\
\hline 2 & SPA & 7.04 & 6.88 & 0.962 & 0.862 & 0.252 & 0.262 & 0.042 \\
\hline 3 & SHW & 7.2 & 5.6 & 1 & 0.758 & 0.258 & 0.222 & 0.021 \\
\hline 4 & HDA & 3.84 & 3.16 & 0.658 & 0.581 & 0.157 & 0.128 & 0.002 \\
\hline 5 & FMD & 0.32 & 6.32 & 0.49 & 0.833 & 0.015 & 0.249 & 0 \\
\hline 6 & DH & 8 & 5.12 & 1 & 0.714 & 0.283 & 0.205 & 0.017 \\
\hline 7 & DEU & 2.16 & 5.16 & 0.658 & 0.714 & 0.092 & 0.209 & 0.003 \\
\hline 8 & DTDRC & 6.04 & 7.04 & 0.926 & 0.862 & 0.231 & 0.273 & 0.074 \\
\hline 9 & $\mathrm{~F}$ & 2.04 & 2.88 & 0.581 & 0.568 & 0.086 & 0.115 & 0 \\
\hline 10 & TEDC & 3.92 & 5.76 & 0.676 & 0.806 & 0.154 & 0.222 & 0.011 \\
\hline 11 & $\mathrm{G}$ & 7.96 & 6.48 & 1 & 0.806 & 0.281 & 0.246 & 0.031 \\
\hline 12 & PDA & 2.76 & 3.6 & 0.658 & 0.625 & 0.121 & 0.155 & 0.001 \\
\hline 13 & REA & 1.28 & 3.96 & 0.568 & 0.694 & 0.049 & 0.166 & 0.002 \\
\hline 14 & B & 0 & 4.88 & 0.25 & 0.758 & 0 & 0.193 & 0 \\
\hline 15 & NRED & 2.32 & 5.44 & 0.595 & 0.735 & 0.08 & 0.219 & 0.004 \\
\hline 16 & LBSE & 5.24 & 4.24 & 0.833 & 0.658 & 0.199 & 0.179 & 0.005 \\
\hline 17 & TD & 3.52 & 3.96 & 0.641 & 0.658 & 0.142 & 0.167 & 0.002 \\
\hline 18 & DDA & 4.28 & 3.88 & 0.735 & 0.658 & 0.186 & 0.163 & 0.003 \\
\hline 19 & C & 8 & 4.2 & 1 & 0.658 & 0.283 & 0.175 & 0.013 \\
\hline 20 & ISCO & 7.04 & 4.2 & 1 & 0.694 & 0.259 & 0.172 & 0.02 \\
\hline 21 & CC & 6.4 & 4.2 & 0.893 & 0.676 & 0.223 & 0.176 & 0.015 \\
\hline 22 & CA & 3.36 & 3.04 & 0.641 & 0.61 & 0.128 & 0.132 & 0 \\
\hline 23 & DM & 5.56 & 3.36 & 0.806 & 0.625 & 0.194 & 0.141 & 0.004 \\
\hline 24 & UU & 6.72 & 6.44 & 0.862 & 0.806 & 0.244 & 0.244 & 0.02 \\
\hline 25 & DPFAL & 3.92 & 3.96 & 0.676 & 0.658 & 0.154 & 0.167 & 0.001 \\
\hline 26 & NGDC & 8 & 3.56 & 1 & 0.625 & 0.283 & 0.153 & 0.005 \\
\hline
\end{tabular}

The numerical value of the frequency of public institutions meeting with each other was calculated as 425. The maximum number of bonds that can occur in the network is $650(n(n-1)=26.25=650)$. Based on this number of bonds, the overall density of the network was calculated as $425 / 650=0.654$. For a network of 26 public institutions, this value is seen to have a density above average. $65.4 \%$ of the maximum number of ties that can occur between the actors are in the network. Public institutions; It can be said that the reliability of public institutions among each other about real estate valuation is above the middle level.

Survey Question 5: Each organization that uses or produce data on real estate valuation was asked the question "Which is the guiding and responsible body to undertake the task of gathering institutional structuring under a single roof?". Network and centrality graphs were created using the data obtained from the answers to this question. Actors and data access network among actors is shown in Fig. 5.

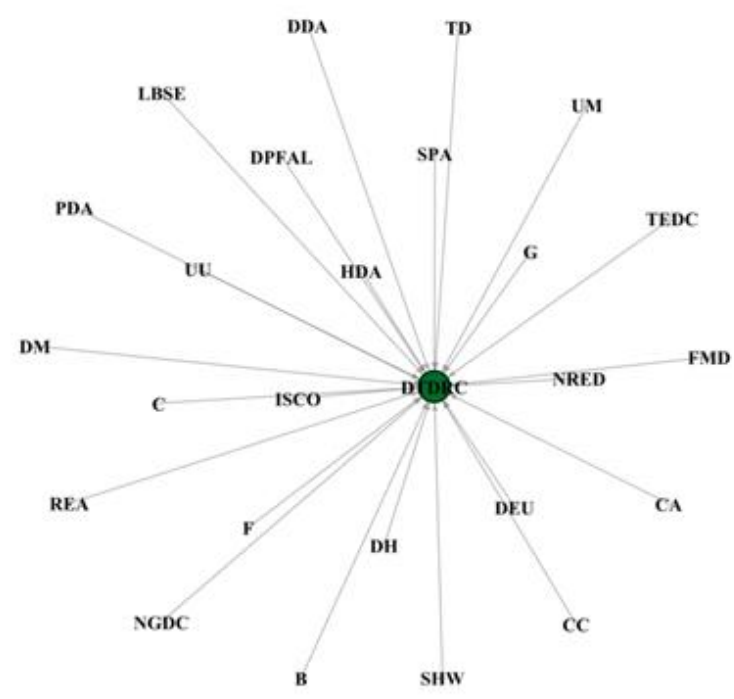

Figure 5. Network map of actors and links between actors according to answers to the fourth question 
Table 8. " Which is the guiding and responsible body to undertake the task of gathering institutional structuring under a single roof ?" in-out degree, in-out closeness, in-out eigenvalues and between proximity values results for this question are:

\begin{tabular}{lllllllll}
\hline No & Institutions & OutDeg & Indeg & OutClose & InClose & OutEigen & InEigen & Between \\
\hline 1 & UM & 0.04 & 0 & 0.51 & 0.5 & 1 & 0 & 0 \\
2 & SPA & 0.04 & 0 & 0.51 & 0.5 & 0 & 0 & 0 \\
3 & SHW & 0.04 & 0 & 0.51 & 0.5 & 0 & 0 & 0 \\
4 & HDA & 0.04 & 0 & 0.51 & 0.5 & 0 & 0 & 0 \\
5 & FMD & 0.04 & 0 & 0.51 & 0.5 & 0 & 0 & 0 \\
6 & DH & 0.04 & 0 & 0.51 & 0.5 & 0 & 0 & 0 \\
7 & DEU & 0.04 & 0 & 0.51 & 0.5 & 0 & 0 & 0 \\
8 & DTDRC & 0 & 1 & 0.5 & 1 & 0 & 0 & 0 \\
9 & F & 0.04 & 0 & 0.51 & 0.5 & 0 & 0 & 0 \\
10 & TEDC & 0.04 & 0 & 0.51 & 0.5 & 0 & 0 & 0 \\
11 & G & 0.04 & 0 & 0.51 & 0.5 & 0 & 0 & 0 \\
12 & PDA & 0.04 & 0 & 0.51 & 0.5 & 0 & 0 & 0 \\
13 & REA & 0.04 & 0 & 0.51 & 0.5 & 0 & 0 & 0 \\
14 & B & 0.04 & 0 & 0.51 & 0.5 & 0 & 0 & 0 \\
15 & NRED & 0.04 & 0 & 0.51 & 0.5 & 0 & 0 & 0 \\
16 & LBSE & 0.04 & 0 & 0.51 & 0.5 & 0 & 0 \\
17 & TD & 0.04 & 0 & 0.51 & 0.5 & 0 & 0 & 0 \\
18 & DDA & 0.04 & 0 & 0.51 & 0.5 & 0 & 0 & 0 \\
19 & C & 0.04 & 0 & 0.51 & 0.5 & 0 & 0 & 0 \\
20 & ISCO & 0.04 & 0 & 0.51 & 0.5 & 0 & 0 & 0 \\
21 & CC & 0.04 & 0 & 0.51 & 0.5 & 0 & 0 & 0 \\
22 & CA & 0.04 & 0 & 0.51 & 0.5 & 0 & 0 \\
23 & DM & 0.04 & 0 & 0.51 & 0.5 & 0 & 0 \\
24 & UU & 0.04 & 0 & 0.51 & 0.5 & 0 & 0 \\
25 & DPFAL & 0.04 & 0 & 0.51 & 0.5 & 0 & 0 \\
26 & NGDC & 0.04 & 0 & 0.51 & 0.5 & 0 & 0 \\
\hline
\end{tabular}

It is understood from the calculated in-degree centrality values that institution "DTDRC" is found to be the most directing and responsible institution by other institutions in the survey. On the other hand, all institutions with the lowest in the degree of centrality were determined to be the least needed institutions by other institutions.

\subsection{Conclusions on the Roles of Organizations in the Network}

Centrality measurements are important in determining the positions and roles of institutions in the network. In Table 2, five actor roles defined for social networks have been identified in the Social Network Analysis Criteria section. In order for the determination of roles, institutions with high values regarding degree, closeness and between centrality measurements are shown.

Star: The central actors in the network were star roles. When the degree, closeness and between chart values are considered, the institutions that are the star of the network are DTDRC, SPA, UM, REA, B and G. These institutions are also in a critical position for social networking because they have the most direct connections. The active involvement of these institutions in the network appears to play an important role in terms of network mobility.

Liaison: It connects two different groups within the social network structure and identifies discrete actors who are not included in these two groups. When the analysis of social network structures is observed/ examined, it is seen that there are not two independent groups within each other, but also there are no institutions that act as linkages and are separated from the groups.

Bridge: The role of the actor is defined as being a member of several groups and providing the connection with other groups. When the analysis of the social network structures is examined, there are no institutions in the role of bridges since there are no two or more blocks in this social network.

Gatekeeper: It is defined as the actor who mediates or controls the flow of information within the social network structure. It is possible to determine the intermediary institutions with the help of measurements of the centrality. When Table number? Is examined in this context, it can be seen that DTDRC, UM, C, G and SPA are gatekeeper institutions. These institutions have a high potential to control the flow of data between institutions within the network and are intermediaries of shared data. If these institutions leave the network, it may be possible to break the relationship of other institution pairs.

Isolate: It refers to those institutions that have little connection with other institutions within the social network structure. Degrees centrality table results are the analysis values that allow the identification of private institutions within the network. When the degree centrality charts are analyzed, it is seen that TD, DPFAL, CA, HAD and DM institutions have the lowest degree centeredness within the network. It is clear that these actors have low effectiveness in terms of accessing, sharing data and participating in communication within the network. In order to increase the mobility of the network, it is essential to identify the institutions in this isolated role rather than randomly increasing communication and data exchange. 


\section{CONCLUSION}

In this study, awareness of institutions producing or using spatial data is tried to be revealed. Thus, it is aimed to contribute to the ongoing future planning process on Real Estate Appraisal. The relation between spatial data for real estate appraisal and all sectors doing business have been examined from the social side, not from the technical side. It is tried to put forward with the "social networks" the system of working together, which the institutions have created unconsciously and which do not adhere to an absolute rule. It is thought that these results and evaluations can be reflected in the whole country.

General evaluation; The overall inter-institutional assessments in connection with the characteristics of the resulting networks are summarized below:

- A large number of institutions in different fields of activity communicate with each other in the areas they need.

- The information or data requested from the institutions is not at a level that will contribute to the development of the strategy of the institution in an advanced dimension.

- The personnel of the institutions have a moderate level of awareness in terms of operating and achieving quality. However, their request for such data sharing is at the forefront.

- It can be said that there is a demand for access to information and data of some institutions, but the level and quality of this demand is generally insufficient.

- It is seen that some institutions are not in a very useful position in the network relationship and do not have any mobility to take part in the Real Estate Appraisal business.

- It can be said that the institutions are willing and conscious about consulting each other in the decision-making processes, but there is not much mutual contribution yet.

- It is understood from the survey that there are many deficiencies in the institutions regarding technological infrastructure, which is considered to be one of the essential components of Real Estate Appraisal.

- It is determined that the qualified and trained personnel in the institutions are insufficient in terms of quantity and quality. It is understood from the survey data that there are no in-service support programs in parallel with the developing technology.

As a result, the current study has made many conclusions and evaluations visible about, how real estate appraisal function is; which institutions play an active role in this matter, which institutions produce and use the most data. Therefore, it is possible to shed light on which institutions should be taken into consideration in all kinds of arrangements and initiatives for real estate appraisal.

\section{ACKNOWLEDMENT}

This study was supported by Usak University, Scientific Research Projects Coordination Unit with project number (2016 / MF012).

\section{REFERENCES}

Barabási A L (2016). Network science. Cambridge university press.

Borgatti S P \& Molina J L (2003). Ethical and strategic issues in organizational social network analysis. The Journal of Applied Behavioral Science, 39(3), 337349. DOI: $10.1177 / 0021886303258111$

Borgatti S P, Mehra A, Brass D J \& Labianca G (2009). Network analysis in the social sciences. Science, 323(5916), 892-895. DOI: 10.1126/science.1165821

Borgatti S P \& Ofem B (2010). Social network theory and analysis. Social network theory and educational change, 17-29.

Borgatti S P, Everett M G \& Johnson J C (2018). Analyzing social networks. Sage. ISBN: 978-1-5264-0409-1

Burt R S \& Minor M J (1983). Applied network analysis: A methodological introduction. Sage Publications, Inc.

Carrington P J, Scott J \& Wasserman S (2005). Models and methods in social network analysis. Cambridge university press, 28

Charalabidis Y, Janssen M \& Krcmar H (2015). Introduction to the big, open, and linked data (BOLD), analytics, and interoperability infrastructures in Government Minitrack. 48th Hawaii International Conference on System Sciences, Kauai, HI, USA. DOI: $10.1109 /$ HICSS.2015.248

Diallo S Y, Gore R J, Barraco A, Padilla J J \& Lynch C (2016). Quantitative performance metrics for evaluation and comparison of middleware interoperability products. The Journal of Defense Modeling and Simulation, 13(2), 161-169. DOI: $10.1177 / 1548512915570143$

Ertas M (2019). Education for real estate valuation in Turkey. International Journal of Engineering and Geosciences, 4(1), 8-15. DOI: 10.26833/ijeg.416336

Çay T, Toklu, N \& Esen Ö (2017). Evaluation of land reform policies in Turkey. International Journal of Engineering and Geosciences, 2(2), 63-67. DOI: 10.26833/ijeg.297223

Freeman L C (2004). The development of social network analysis. A Study in the Sociology of Science, Empirical Press, Vancouver, BC Canada, 1. ISBN: $1-59457-714-5$

Freeman L C (1996). Some antecedents of social network analysis. Connections, 19(1), 39-42.

Freeman L C, White D R \& Romney A K (2017). Research methods in social network analysis. Routledge, New York, USA.

Friedman J P, Harris J C \& Lindeman J B (2017). Dictionary of real estate terms. Simon and Schuster.

Iversen T, Anell A, Häkkinen U, Kronborg C \& Ólafsdóttir $\mathrm{T}$ (2016). Coordination of health care in the Nordic 
countries. Nordic Journal of Health Economics, 4(1), 41-55. DOI: $10.5617 /$ njhe. 2846

Güney C, Doğru A Ö, Başaraner M, Çelik R N, Uluğtekin N, Özlüdemir T \& Keskin M (2015). “TUCBS Açmazı” ve Açık Bir Ulusal Mekansal Veri Altyapısına Yönelim. 15. Türkiye Harita Bilimsel ve Teknik Kurultayı. (in Turkish).

Jablin F M \& Putnam L L (2001). The new handbook of organizational communication: Advances in Theory, Research and Methods. Sage Pub.

Jablin F M \& Putnam L L (2004). The new handbook of organizational communication: Advances in theory, research, and methods. Sage Pub.

Jones A T, Friedkin N E \& Singh A K (2017). Modeling the Co-evolution of Committee Formation and Awareness Networks in Organizations. Complex Networks and their Applications. Springer, Cham, 881-894. DOI: 10.1007/978-3-319-72150-7_71

Kauko T (2018). Pricing and sustainability of urban real estate. Routledge.

Knoke D \& Yang S (2019). Social network analysis. Sage, 154.

Krause A L \& Bitter C (2012). Spatial econometrics, land values and sustainability: Trends in real estate valuation research.Cities, 29, S19-S25. DOI: 10.1016/j.cities.2012.06.006

Lucius D I (2001). Real options in real estate development. Journal of Property Investment \& Finance, 19(1), 73-78.

Lundsgaarde E, Fejerskov A M \& Skovgaard J (2018). Analysing climate finance coordination. DIIS.

MacGregor B D, Schulz R \& Green R K (2018). Routledge Companion to Real Estate Investment. Routledge.

Moreno J L \& Jennings H H (1938). Statistics of social configurations. Sociometry, 342-374.

Nanda A (2019). Residential Real Estate: Urban \& Regional Economic Analysis. Routledge.

Ozbek E D, Zlatanova S, Aydar S A \& Yomralioglu T (2016). 3D Geo-Information requirements for disaster and emergency management. International Archives of the Photogrammetry, Remote Sensing \& Spatial Information Sciences, 41.

Polat Z A \& Ustuner M \& Alkan M (2015). On the way to vision of cadastre 2034: Cadastre 2014 performance of Turkey. FIG working week, Sofia, Bulgaria.

Saralioğlu M Ö, Demir O, Coruhlu Y E \& Saralioğlu E (2019). Data model design for qualified naturalprotected area in Turkey. Survey Review, 51(365), 154-165. DOI: 10.1080/00396265.2017.1388960

Scott J (1988). Social network analysis. Sociology, 22(1), 109-127. DOI: $10.1177 / 0038038588022001007$

Seevers M T, Johnson B R \& Darnold T C (2015). Social Networks in the Classroom: Personality Factors as Antecedents of Student Social Capital. American Journal of Business Education, 8(3), 193-206.
Smith A \& Wen X (2017). Investing in institutions for cooperation. Journal of the Economic Science Association, 3(1), 75-87. DOI: $10.1007 /$ s40881017-0033-2

Smith C (2016). U.S. Patent Application No. 14/673,810.

Taktak F (2013). Social/organizational network analysis within the scope nsdi. PhD Thesis, Yıldı Technical University, Turkey (in Turkish).

Taktak F \& Demir H (2019). Relations that show the network potential for spatial data sharing. Technical Gazette, 26(2), 346-354. DOI: $\quad$ 10.17559/TV20170920100230

Thibaut A, Bruno M A, Chatelle C, Gosseries O et al. (2012). Metabolic activity in external and internal awareness networks in severely brain-damaged patients. Journal of Rehabilitation Medicine, 44(6), 487-94. DOI: $10.2340 / 16501977-0940$

Tichy N M, Tushman M L \& Fombrun C (1979). Social network analysis for organizations. Academy of management review, 4(4), 507-519. DOI: 10.5465/amr.1979.4498309

Ujwary-Gil A (2019). Organizational Network Analysis: Auditing Intangible Resources. Routledge.

Unel F B, Yalpir S \& Gulnar B (2017). Preference changes depending on age groups of criteria affecting the real estate value. International Journal of Engineering and Geosciences, 2(2), 41-51. DOI: 10.26833/ijeg.297271

Vaubel R (2016). 3 Institutions for European Cooperation. Breaking Up Is Hard To Do: Britain and Europe's Dysfunctional Relationship: Britain and Europe's Dysfunctional Relationship, 40.

Yu S M (2016). Real Estate Education. Singapore's Real Estate: 50 Years of Transformation, 241-252.

Zutshi A, Grilo A \& Jardim-Goncalves R (2012). The business interoperability quotient measurement model. Computers in Industry, 63(5), 389-404. DOI: 10.1016/j.compind.2012.01.002

Wang C, Dai S \& Xu H (2018). Estimating the land opportunism of hotel investment in generating real estate appreciation and firms' market value. Land use policy, 77, 752-759. DOI: 10.1016/j.landusepol.2018.06.015

Wang S, Chen X \& Szolnoki A (2019). Exploring optimal institutional incentives for public cooperation. Communications in Nonlinear Science and Numerical Simulation,79, 104914. DOI: 10.1016/j.cnsns.2019.104914

Wasserman S \& Faust K (1994). Social network analysis: Methods and applications, Cambridge university press, 8.

Whitney J, Woodworth B N, Sohaney M \& Hacking L J (2009). U.S. Patent Application No. 12/403,324. 